\title{
iRobot Corporation's Intellectual Property: Accounting For Research And Development Under U.S. GAAP Versus IFRS
}

Robert M. Bowen, University of San Diego, USA

Jane Jollineau, University of San Diego, USA

Loren Margheim, University of San Diego, USA

\begin{abstract}
Founded by MIT scientists in 1990, iRobot Corporation designed, developed, and sold consumer and military robots to help people complete 'dull, dirty or dangerous' tasks in real-world situations. The purpose of this case study is to stimulate discussion about intellectual property and how it should be measured and reported. Under U.S. generally accepted accounting principles (GAAP), iRobot reported no asset related to their internally generated intellectual property - despite over 20 years of intensive research in robotics. In contrast, international financial reporting standards (IFRS) permitted firms to treat certain research and development $(R \& D)$ activities as an asset. By comparing U.S. GAAP and IFRS treatments of $R \& D$, we provide an interesting example of the range of potential financial reporting effects across alternative accounting methods. Further, the case requires that students wrestle with the implications of moving from more rule-based accounting (U.S. GAAP) to more principles-based accounting (IFRS). How might U.S. managers, auditors, and investors likely respond? A teaching note is available.
\end{abstract}

Keywords: iRobot; Intellectual Property (IP); U.S. GAAP; IFRS; Research and Development (R\&D); Balance Sheet; Income Statement

\section{INTRODUCTION}

tiRobot, we believe there is a better way to accomplish many of the dull, dirty and dangerous tasks
that face us today.

iRobot designed, developed, and marketed robots that helped people complete "dull, dirty or dangerous" tasks in dynamic real-world situations. The company's robots used behavior-based, artificial-intelligence systems to undertake complex tasks. In contrast, most robotic manufacturing equipment or entertainment systems were designed to repeat routine actions in specific, known environments.

On March 23, 2010, iRobot celebrated 20 years of innovation in robotics. Despite its track record of innovation, iRobot reported an accumulated deficit of \$7.6 million in their balance sheet as of year-end 2009 (Exhibit 1). While this deficit had decreased substantially due to annual profits in the recent years (Exhibit 2), management cautioned:

Because we operate in a rapidly evolving industry, there are challenges to predicting our future operating results, and we cannot be certain that our revenues will grow at rates that will allow us to maintain profitability during every fiscal quarter, or even every fiscal year. In addition, we only have limited operating history on which you can base your evaluation of our business. Failure to maintain profitability may result in our inability to access capital under our existing credit arrangements. (2009 10-K, p. 19)

\footnotetext{
${ }^{1}$ From 2005 Annual letter to shareholders, p. 1. 
Exhibit 1: iRobot Corporation's Consolidated Balance Sheets

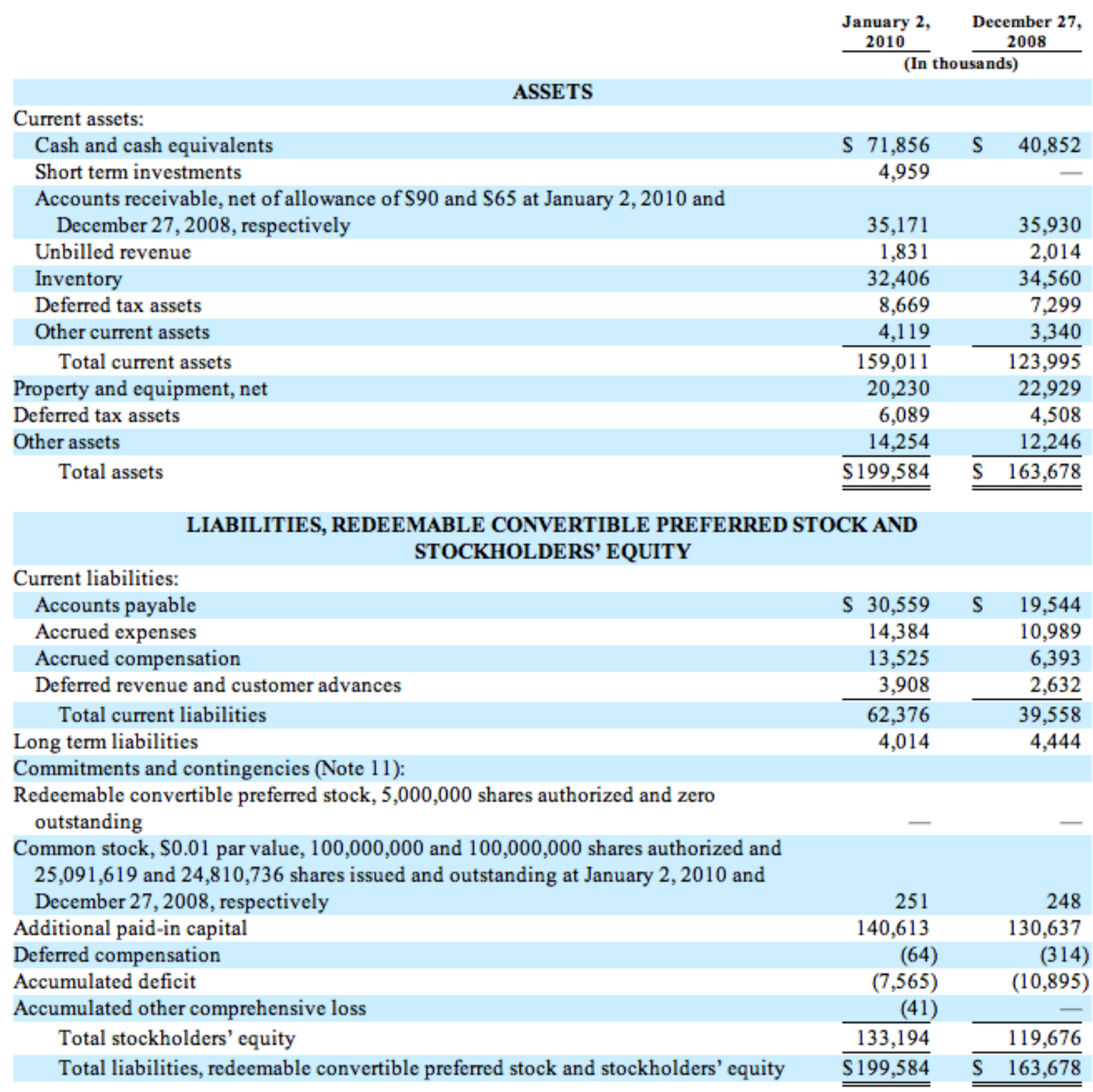

Source: 2009 iRobot 10-K 
Exhibit 2: iRobot Corporation's Consolidated Statements Of Operations and Summary Balance Sheets (2005 - 2009)

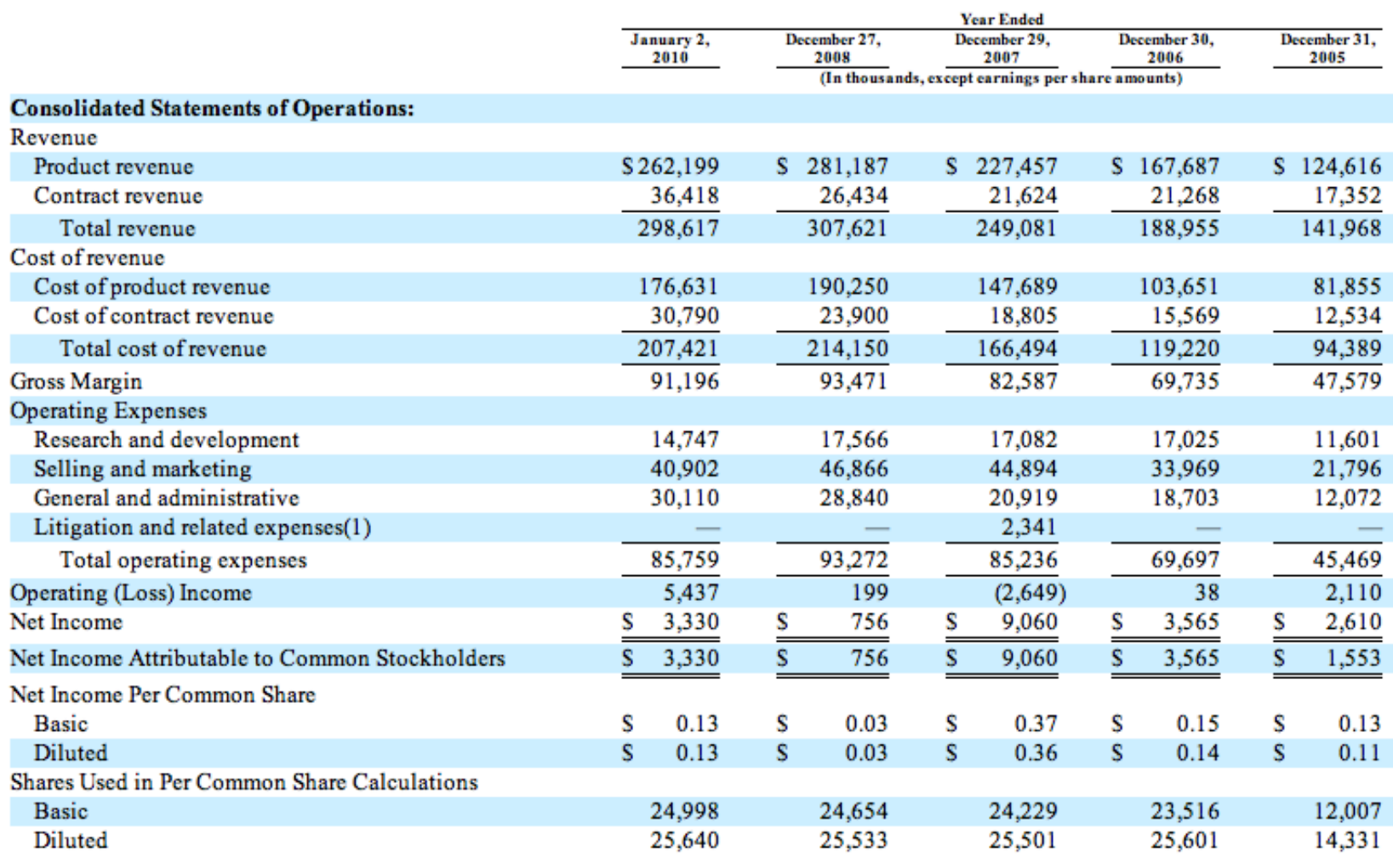

(1) Consists of costs for litigation relating to lawsuits filed against Robotic FX, Inc. and Jameel Ahed, as well as settlement costs related to the litigation.

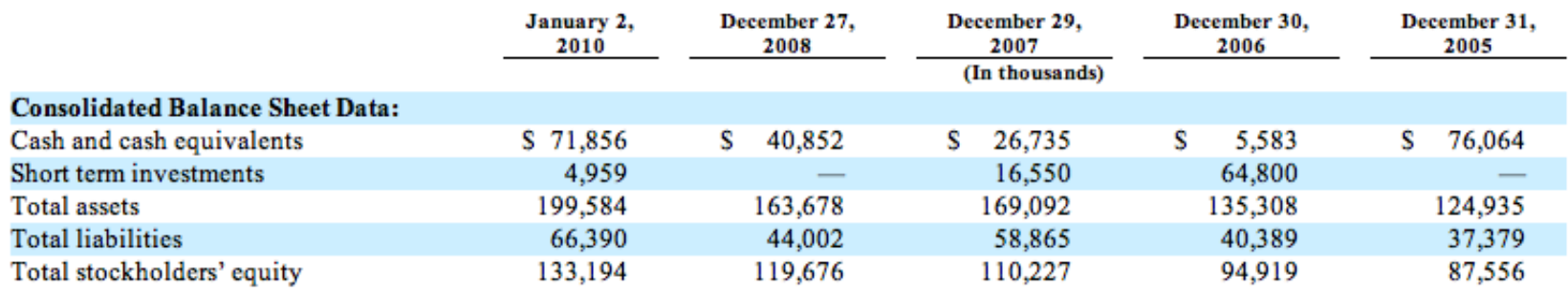

Source: 2009 iRobot 10-K

\section{BACKGROUND}

iRobot was founded in 1990 by scientists at the Massachusetts Institute of Technology. Over the subsequent two decades, iRobot developed proprietary technologies incorporating advanced concepts of navigation, mobility, manipulation and artificial intelligence. "iRobot's mission is to change the world by building practical robots that make a difference, while delivering increased value to our shareholders." ${ }^{2}$ iRobot became a public company in November 2005 when, for the first time, a robot sounded the opening bell on the NASDAQ stock exchange. On December 31, 2009, iRobot's common stock (ticker $=$ IRBT) closed at $\$ 17.60$ per share, indicating a market value of equity in excess of $\$ 440$ million.

In 2002, iRobot launched its two flagship products - the Roomba for home floor sweeping and the PackBot military robot to support dangerous wartime activities. iRobot's consumer products perform time-consuming dull and dirty domestic chores. The Roomba (Exhibit 3) was intended to replace the standard home floor vacuum

\footnotetext{
${ }^{2}$ Colin Angle, iRobot chairman and CEO, March 23, 2010.
} 
cleaner and came in several models, ranging in retail price from \$129 to \$549. iRobot sold over 5 million Roomba vacuuming robots through 2009, but market penetration was still less than $5 \%$ of North American homes. The Scooba floor-washing robot (Exhibit 4) was introduced in 2004 to automatically sweep, wash, scrub and dry hard floors. The Scooba came in several models, ranging in retail price from \$299 to \$499. iRobot sold its consumer robots through the company's on-line store and other national retailers, including Costco, Sears, Target, and Home Depot.

\section{Exhibit 3: Consumer iRobot 'Roomba' Vacuum Cleaner}

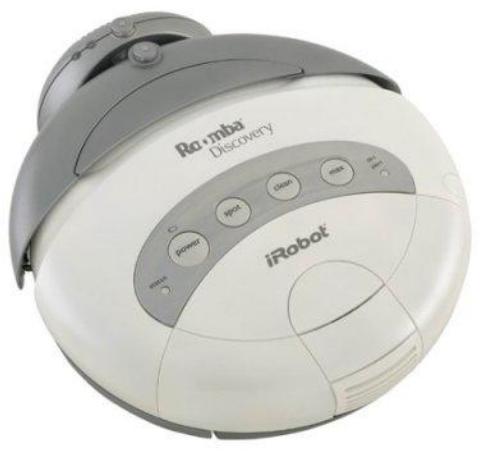

Exhibit 4: Consumer iRobot 'Scooba' Hard Surface Floor Cleaner

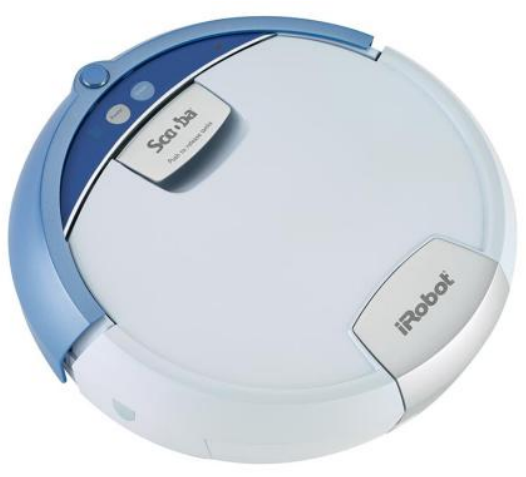

iRobot's PackBot tactical military robot performed dangerous activities, such as battlefield reconnaissance and bomb disposal (Exhibit 5). PackBot robots varied greatly in price depending on their configuration. By yearend 2009, iRobot had delivered more than 2,900 of these 'government and industrial' robots to the U.S. government, foreign governments, domestic police and first responders. ${ }^{3}$ Most were deployed on missions in Afghanistan and Iraq.

Exhibit 5: Military 'PackBot' Robot On Rough Terrain And Soldier Carrying PackBot
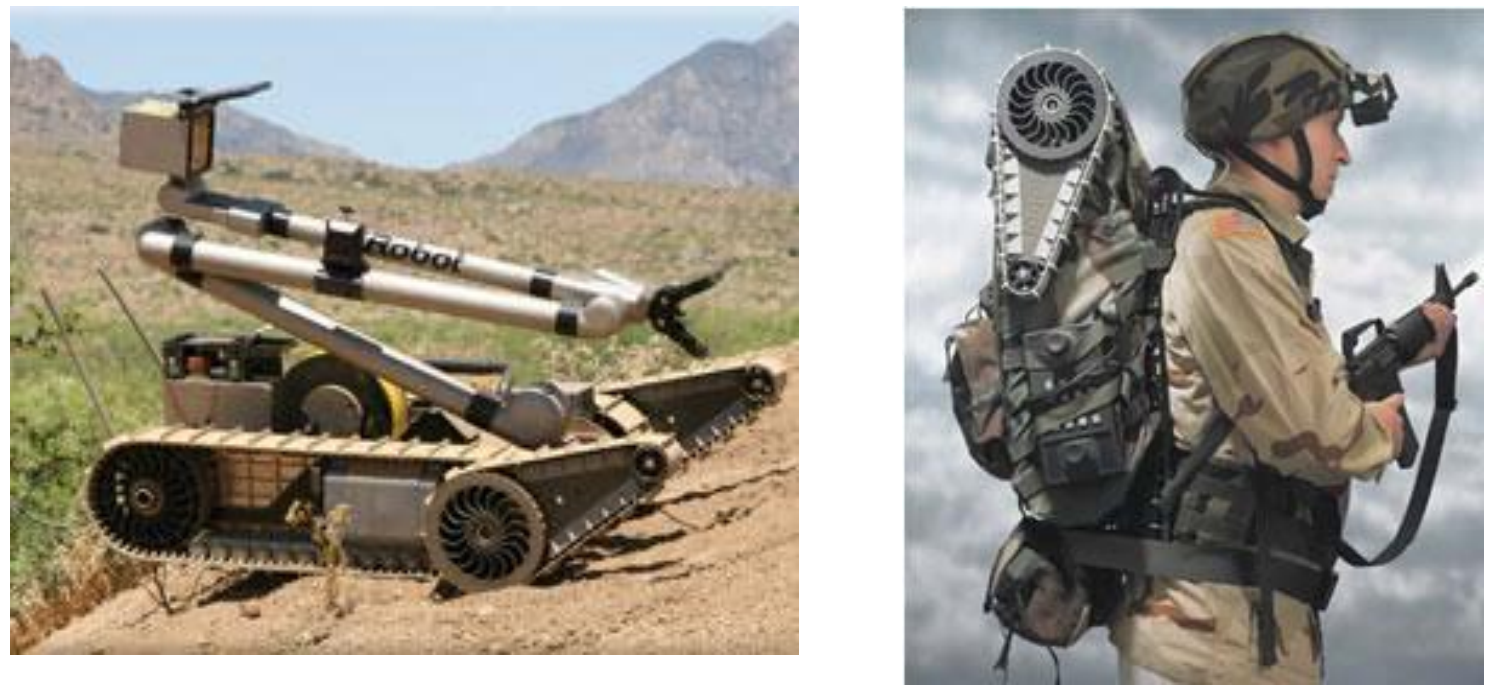

${ }^{3}$ Foreign governments included the United Kingdom, France, Germany, Sweden, Norway, Israel, Australia, Republic of Korea, and Singapore 


\section{PROSPECTS FOR GROWTH}

Management believed iRobot's expertise in robot design and engineering put the company in a position to experience significant growth in the coming years:

Our significant expertise in robot design and engineering, combined with our management team's experience in military and consumer markets, positions us to capitalize on the growth we expect in the market for robot-based products. We believe that the sophisticated technologies in our existing consumer and military applications are adaptable to a broad array of markets, such as law enforcement, homeland security, commercial cleaning, elder care, oil services, home automation, landscaping, agriculture, construction, and other vertical markets. Our strategy is to maintain a leadership position in pursuing new applications for robot solutions by leveraging our ability to innovate, to bring new products to market quickly, to reduce costs through design and outsourcing capabilities, and to commercialize the results of our research, much of which is government funded. (2009 10-K, $\mathrm{p}$. 3)

\section{INTELLECTUAL PROPERTY}

iRobot participated in the fast changing, competitive, high-technology robotics industry. iRobot's 200910 $\mathrm{K}$ listed (on p. 24) 13 direct competitors in robotic floor cleaning, including $\mathrm{AB}$ Electrolux and Samsung Electronics, and three direct competitors in small unmanned vehicles, including Remotec, a division of Northrop Grumman. The 10-K also noted that established government contractors were working on unmanned systems, including Lockheed Martin, Boeing and General Dynamics.

iRobot management believed its ongoing success was dependent on its proprietary technology, the intellectual skills of its employees, and the ability of these employees to continue to innovate (2009 10-K, p. 14). iRobot's future performance would be determined by the quality of its current and future intellectual property, its ability to protect it, and its ability to excel in product development and customer support.

\section{Litigation and Related Expenses}

Section 1A of the iRobot 2009 10-K entitled 'Risk Factors' noted:

If we fail to protect, or incur significant costs in defending, our intellectual property and other proprietary rights, our business and results of operations could be materially harmed. (2009 10-K)

In fiscal 2007, iRobot incurred $\$ 2.3$ million in litigation and settlement-related costs pertaining to filling two similar lawsuits in an attempt to protect their intellectual capital.

On August 17, 2007, we filed a lawsuit in Massachusetts Superior Court against Robotic FX, Inc. and Jameel Ahed alleging, among other things, misappropriation of trade secrets and breach of contract, and seeking both injunctive and monetary relief. The case was subsequently removed to the United States District Court for the District of Massachusetts. On November 2, 2007, the court issued a preliminary injunction and on December 21, 2007, issued a permanent injunction against Robotic FX, Inc. and Mr. Ahed preventing the sale of products using certain of our trade secrets, including the Robotic FX Negotiator product.

In addition, on August 17, 2007, we filed a lawsuit in the United States District Court for the Northern District of Alabama against Robotic FX, Inc. alleging willful infringement of two patents owned by us and seeking both injunctive and monetary relief. On December 21, 2007, the court entered a judgment that Robotic FX, Inc. knowingly infringed on both asserted patents.

In a related settlement, Robotic FX, Inc. will be dissolved and certain residual assets will be retained by us at our election. Mr. Ahed is prohibited from participating in competitive activities in the robotics industry for five years. 
Our cumulative litigation and settlement-related expenditures associated with this dispute are expected to total approximately \$3.0 million, including an obligation to make cash payments up to \$0.7 million through 2012, contingent upon Mr. Ahed and Robotic FX, Inc. continuing to meet obligations pursuant to various agreements, including, but not limited to, certain non-competition provisions. These contingent payments will be expensed when and if earned. (2007 10-K, p. 35)

\section{ACCOUNTING FOR RESEARCH AND DEVELOPMENT (R\&D)}

Despite the apparent importance of iRobot's intellectual property, current U.S. accounting standards required that iRobot expense $R \& D$ costs as incurred. Exhibit 6 provides annual R\&D expense from 2003 through 2009. Some of iRobot's R\&D was funded by governments and other third parties. Thus, iRobot's reported R\&D expense was far less than its total expenditures as described in their research and development note below:

We believe that our future success depends upon our ability to continue to develop new products and product accessories, and enhancements to and applications for our existing products. For the years ended January 2, 2010, December 27, 2008, and December 29, 2007, our research and development expenses were \$14.7 million, $\$ 17.6$ million and \$17.1 million, respectively. In addition to our internal research and development activities for the years ended January 2, 2010, December 27, 2008, and December 29, 2007, we have incurred research and development expenses under funded development arrangements with governments and industrial third parties of $\$ 30.8$ million, \$23.9 million, and \$18.8 million, respectively. Of our total research and development spending in 2009, 2008, and 2007, approximately 63.9\%, 51.7\%, and 37.9\%, respectively, was funded by government-sponsored research and development contracts. For the years ended January 2, 2010, December 27, 2008, and December 29, 2007, the combined investment in future technologies, classified as cost of revenue and research and development expense, was $\$ 45.5$ million, $\$ 41.5$ million, and $\$ 35.9$ million, respectively. We intend to continue our investment in research and development to respond to and anticipate customer needs and to enable us to introduce new products over the next few years that will continue to address our existing market sectors. (2009 10-K, p. 13)

Exhibit 6: iRobot Corporation's Schedule Of Annual Research And Development Costs (in \$ thousands)

\begin{tabular}{|c|c|c|c|c|c|c|c|}
\hline & $\underline{2009}$ & $\underline{2008}$ & $\underline{2007}$ & $\underline{2006}$ & $\underline{2005}$ & $\underline{2004}$ & $\underline{2003}$ \\
\hline $\begin{array}{l}\mathrm{R} \& \mathrm{D} \text { expense } \\
\text { as reported }\end{array}$ & $\$ 14,747$ & $\$ 17,556$ & $\$ 17,082$ & $\$ 17,025$ & $\$ 11,601$ & $\$ 5,504$ & $\$ 3,848$ \\
\hline $\begin{array}{l}\text { Contract R\&D } \\
\text { expense }^{5}\end{array}$ & $\$ 30,790$ & $\$ 23,900$ & $\$ 12,534$ & $\$ 15,569$ & $\$ 18,805$ & $\$ 8,371$ & $\$ 6,143$ \\
\hline
\end{tabular}

Sponsored R\&D is shown in the income statements as contract revenue and the related expense, cost of contract revenue (Exhibit 2). The relative magnitude of contract revenue and cost of contract revenue is shown in Exhibit 7. 
Exhibit 7: Excerpt from Managements' Discussion and Analysis shown:

The following table sets forth our results of operations as a percentage of revenue for the periods

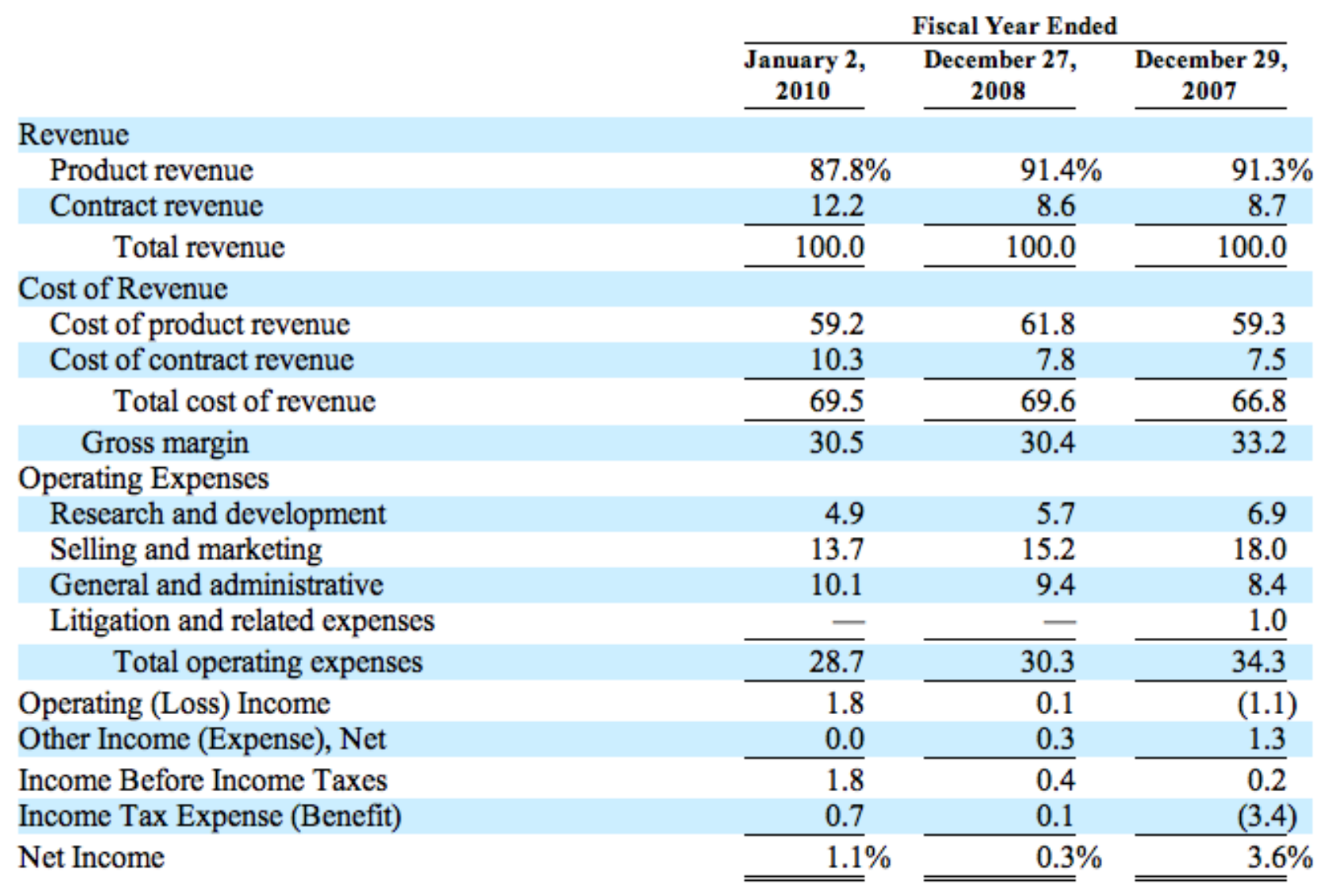

Source: 2009 iRobot 10-K

\section{MANAGEMENT'S REVIEW OF IFRS}

Assume that in early 2010, iRobot senior management was reviewing the implications of adopting international financial reporting standards (IFRS) on its accounting for intellectual property, including R\&D. Management was especially concerned about the effect of the standards on reported profitability.

Management's review of International Accounting Standard \#38 (summarized in Exhibit 8) produced the following practical questions:

1. Does U.S. GAAP adequately capture the importance of intellectual property at iRobot?

2. How much flexibility does iRobot's management have in reporting capitalized development costs under IFRS?

3. Given this flexibility, how much of iRobot's R\&D should be classified as development costs subject to capitalization as an asset under IFRS?

4. Should iRobot adopt the 'cost' or 'revaluation' method for reporting capitalized development costs under IFRS?

5. What will be the effect on reported operating earnings and assets if iRobot capitalizes development costs under IFRS?

6. What position should iRobot's management take on lobbying for the implementation of IFRS in the U.S.? 


\section{Exhibit 8: iRobot Corporation's \\ Excerpts from International Accounting Standard \#38 On Internally Generated R\&D}

\section{Definitions}

As asset is a resource:

(a) controlled by an entity as a result of past events; and

(b) from which future economic benefits are expected to flow to the entity. (Par. 8)

An intangible asset is an identifiable non-monetary asset without physical substance. (Par. 8)

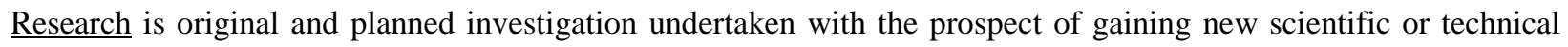
knowledge and understanding. (Par.8)

Development is the application of research findings or other knowledge to a plan or design for the production of new or substantially improved materials, devices, products, processes, systems or services before the start of commercial production or use. (Par. 8)

Fair value of an asset is the amount for which that asset could be exchanged between knowledgeable, willing parties in an arm's length transaction. (Par. 8)

\section{Recognition}

\section{$\underline{\text { General Guidance }}$}

The recognition of an item as an intangible asset requires an entity to demonstrate that the item meets:

(a) the definition of an intangible asset; and

(b) the recognition criteria (see Par. 21 below).

This requirement applies to costs incurred initially to acquire or internally generate an intangible asset and those subsequently incurred to add to, replace part of, or service. Only rarely will subsequent expenditure be recognized in the carrying amount of an intangible asset. This is because such expenditure cannot be distinguished from expenditure to develop the business as a whole. (Par. 18, 20)

An intangible asset shall be recognized if, and only if:

(a) it is probable that the expected future benefits that are attributable to the asset will flow to the entity; and

(b) the cost of the asset can be measured reliably. (Par. 21)

$\underline{\text { Internally-generated }}$

To assess whether an internally generated intangible asset meets the criteria for recognition, an entity classifies the generation of the asset into:

(a) a research phase; and

(b) a development phase.

Although the terms 'research' and 'development' are defined, the terms 'research phase' and 'development phase' have a broader meaning for the purpose of this Standard. (Par. 52)

No intangible asset arising from research (or from the research phase of an internal project) shall be recognized. Expenditure on research (or on the research phase of an internal project) shall be recognized as an expense when it is incurred. (Par. 54) 


\section{Exhibit 8 (Continued): iRobot Corporation's \\ Excerpts from International Accounting Standard \#38 On Internally Generated R\&D}

An intangible asset arising from development (or from the development phase of an internal project) shall be recognized if, and only if, an entity can demonstrate all of the following:

(a) the technical feasibility of completing the intangible asset so that it will be available for use or sale.

(b) its intention to complete the intangible asset and use or sell it.

(c) its ability to use or sell the intangible asset.

(d) how the intangible asset will generate probable future economic benefits.

(e) the availability of adequate technical, financial and other resources to complete the development and to use or sell the intangible asset.

(f) Its ability to measure reliably the expenditure attributable to the intangible asset during its development. (Par. 57)

\section{Measurement}

An entity shall choose either the cost model (Par. 74) or the revaluation model (Par. 75) as its accounting policy. If an intangible asset is accounted for using the revaluation model, all the other assets in its class shall also be accounting for using the same model, unless there is no active market for those assets. A class of intangible assets is a grouping of assets of similar nature and use in an entity's operations. The items within a class of intangible assets are revalued simultaneously. (Par. 72-73)

\section{Cost Model}

After initial recognition, an intangible asset shall be carried at its cost less any accumulated amortization and any accumulated impairment losses. (Par. 74)

\section{$\underline{\text { Revaluation Model }}$}

After initial recognition, an intangible asset shall be carried at a revalued amount, being its fair value at the date of revaluation less any subsequent accumulated amortization and any subsequent accumulated impairment losses. For the purpose of revaluations under this Standard, fair value shall be determined by reference to an active market. Revaluations shall be made with such regularity that at the end of the reporting period the carrying amount of the asset does not differ materially from it fair value. (Par. 75)

If an intangible asset's carrying amount is increased as a result of a revaluation, the increase shall be recognized in other comprehensive income and accumulated in equity under the heading of revaluation surplus. However, the increase shall be recognized in profit or loss to the extent that it reverses a revaluation decrease of the same asset previously recognized in profit or loss. (Par. 85)

If an intangible asset's carrying amount is decreased as a result of a revaluation, the decrease shall be recognized in profit or loss. However, the decrease shall be recognized in other comprehensive income to the extent of any credit balance in the revaluation surplus in respect of that asset. The decrease recognized in other comprehensive income reduces the amount accumulated in equity under the heading of revaluation surplus. (Par. 86)

\section{CASE QUESTIONS}

1. What are indications in the financial statements that iRobot had significant intellectual property?

2. How was R\&D treated under U.S. GAAP? What would be the journal entry to record R\&D related costs in 2009? What would be the effect on profitability if iRobot management reduced R\&D?

3. As a senior manager at iRobot and holding other things equal, how might the accounting treatment of R\&D under U.S. GAAP affect your decisions about investing in R\&D? 
4. As an analyst interested in evaluating the future prospects of iRobot, how would you interpret the dollars spent on R\&D that are reimbursed by governments and other third parties?

5. How is R\&D treated under IFRS? As a senior manager at iRobot, how might the accounting treatment of $R \& D$ under IFRS affect your decisions about investing in R\&D?

6. Assume iRobot senior management wanted to evaluate the effect of the IFRS cost model on its financial statements. The cost model capitalizes development costs and amortizes them over their useful life. Estimate the effect of IFRS on iRobot's operating income and assets for 2005 through 2009. Assume that 1) $80 \%$ of iRobot's annual research and development expense would be classified as development costs under IFRS, 2) the company begins amortizing capitalized development costs at the beginning of the year following the expenditure, (3) the average useful life of capitalized development costs is two years, and (4) the company capitalizes these costs retrospectively. ${ }^{4}$ Ignore any potential tax effects.

7. Which of the following treatments, (i) US GAAP, (ii) IFRS (cost method) or (iii) IFRS (revaluation method), would you prefer in each of the following roles: a) senior management of iRobot, b) partner in charge of the external audit of iRobot's financial statements, and c) a potential investor in the common stock of iRobot? Why?

8. Put yourself in the role of a financial analyst evaluating iRobot's prospects for future profitability. What is your overall view of the ability of financial statements to capture the economics for intellectual-propertyintensive firms such as iRobot?

\section{ACKNOWLEDGMENTS}

This case was prepared using publicly available sources. We acknowledge the helpful comments of Frank Hodge and D. Shores of the University of Washington. Any reference to management actions or motives is purely hypothetical. Funding was provided by a PricewaterhouseCoopers IFRS Ready Grant. Revised, March 2013.

\section{AUTHOR INFORMATION}

Robert M. Bowen, Ph.D., is Distinguished Professor of Accounting at the School of Business Administration, University of San Diego, since September 2012. Previously, he was PricewaterhouseCoopers Professor of Accounting at the Foster School of Business at the University of Washington. His research has appeared in journals such as The Accounting Review, Contemporary Accounting Research, Journal of Accounting and Economics, Journal of Accounting, Auditing and Finance, Journal of Applied Corporate Finance, Journal of Financial and Quantitative Analysis, and Financial Management. He holds a Ph.D. from Stanford University. E-mail: rbowen@sandiego.edu (Corresponding author)

Jane Jollineau, Ph.D., is Distinguished Professor of Accounting at the School of Business Administration, University of San Diego, since September 2012. Previously, she was Deloitte \& Touche Professor of Accounting at the Foster School of Business at the University of Washington. Jane has served as an editor of The Accounting Review (for experimental research) and on the editorial board of four other academic journals. Three of her students have won "outstanding dissertation" awards. Her research has appeared in journals such as The Accounting Review, Journal of Accounting Research, Journal of Management Accounting Research, Behavioral Research in Accounting, Journal of Behavioral Decision Making, Auditing: A Journal of Practice and Theory, and Organizational Behavior and Human Decision Processes. She holds a Ph.D. from Duke University.

Loren Margheim, Ph.D., joined the School of Business Administration at the University of San Diego in 1984, where he currently is Professor and Chair of the Department of Accountancy. His research has appeared in journals such as Journal of Accounting Research, Advances in Accounting, Auditing: A Journal of Theory and Practice, and Accounting Horizons. In 1997 Margheim was appointed associate editor of Advances in Accounting in recognition of his research expertise in behavioral accounting issues. He holds a Ph.D. from Arizona State University.

\footnotetext{
4 "Retrospectively" means that iRobot restates their financial statements as if they had always capitalized development costs. While retrospective treatment may not be allowed under IFRS (IAS \#38, Par. 71), it (i) seems prudent for firms to evaluate the long run effects of capitalization, and (ii) shows students the long run effects of capitalization may not be what they expect.
} 


\section{REFERENCES}

1. Fiscal 2005 iRobot Form 10-K, http://www.sec.gov/edgar.shtml

2. Fiscal 2007 iRobot Form 10-K, http://www.sec.gov/edgar.shtml

3. Fiscal 2009 iRobot Form 10-K, http://www.sec.gov/edgar.shtml

4. International Accounting Standard No. 38, http://www.ifrs.org/ 
NOTES 